\title{
Article \\ Clusters of Skeptical Consumers Based on Technology and AI Acceptance, Perception of Social Media Information and Celebrity Trend Setter
}

\author{
Corina Pelau ${ }^{1, * \mathbb{D}}$, Mihai-Ionut Pop ${ }^{2}$, Irina Ene ${ }^{2}$ and Laura Lazar ${ }^{2}$ \\ 1 Department for Business Administration, In Foreign Languages (UNESCO Chair), Bucharest University of \\ Economic Studies, 010371 Bucharest, Romania \\ 2 Doctoral School in Business Administration, Bucharest University of Economic Studies, \\ 010371 Bucharest, Romania; mihai.pop@digitix.ro (M.-I.P.); irina3ene@yahoo.com (I.E.); \\ laura_lazar10@yahoo.com (L.L.) \\ * Correspondence: corina.pelau@fabiz.ase.ro; Tel.: +40-745-581-208
}

\section{check for} updates

Citation: Pelau, C.; Pop, M.-I.; Ene, I.; Lazar, L. Clusters of Skeptical Consumers Based on Technology and AI Acceptance, Perception of Social Media Information and Celebrity Trend Setter. J. Theor. Appl. Electron. Commer. Res. 2021, 16, 1231-1247. https://doi.org/10.3390/jtaer16050069

\section{Academic Editors:}

Dan-Cristian Dabija, Cristinel Vasiliu and Rebeka-Anna Pop

Received: 20 March 2021

Accepted: 6 April 2021

Published: 9 April 2021

Publisher's Note: MDPI stays neutral with regard to jurisdictional claims in published maps and institutional affiliations.

Copyright: (C) 2021 by the authors. Licensee MDPI, Basel, Switzerland. This article is an open access article distributed under the terms and conditions of the Creative Commons Attribution (CC BY) license (https:/ / creativecommons.org/licenses/by/ $4.0 /)$.

\begin{abstract}
The present consumer is surrounded every day by a huge amount of data and information and is confronted with the need to process the received information. Based on the existing content and the development of user generated content and fake news, consumers develop more and more a skeptical opinion regarding existing media information. In this paper we determine four clusters of consumers based on technology and artificial intelligence (AI) acceptance, skeptical opinion regarding media information, need for validation of received information and the influence of celebrity trend setters. For each of the clusters, we analyze the relationship between the skeptical opinion of consumers related to social media information and some present trends about the development of technologies and AI, the influence of celebrity trend setters and the need to check the received information. The results of the research show that the development of technologies and AI have an influence on the skeptical opinion related to media information for some consumer groups. The celebrity trend setter has a significant influence on the skeptical opinion only for one of the consumer groups. The need for information and news validation is related to the skeptical opinion regarding media information, but in different ways for the determined clusters.
\end{abstract}

Keywords: artificial intelligence; media information; social media; celebrity endorsement; fake news; skeptical opinion; trust

\section{Introduction}

The world we are living in has undergone several transformations caused by digital development and the permanent connection of consumers to mobile devices and social media. In comparison to the last century, the present consumer has constant access to information being frequently over exposed to different types of messages and content in the online environment. Consumers can get information anytime and anywhere but are frequently confronted with exaggerated opinions on facts or even fake messages [1] creating a skeptical opinion of users related to online information. Several studies have shown that an overexposure to information leads frequently to a lower cognitive capability of users to read and acknowledge the entirety of the information [2] or even reduces their media-literacy and ability to think critically [3]. Negative information especially leads to lower social trust in the presented messages [1]

The objective of this research is to determine the impact of present trends on the ability of online consumers to develop skeptical and critical opinions regarding the information presented in the online environment. We analyze the development of a skeptical opinion on news information related to three actual tendencies: technology and artificial intelligence (AI) development, the trust and the need to check the existing information and the influence 
of celebrity trend setters. New technologies and AI development are an important factor of user generated content and they are responsible for the multiplication of news and therefor impact the critical thinking on media and information sources [1,3]. The second relation has been the one related to celebrity endorsement and media information. Traditionally, celebrities have been frequently used in order to attract the attention of the public and therefore they are frequently connected to media information [4]. They frequently increase the credibility of sources, which is an important determinant of the trust towards the presented information [5]. The last factor refers to the need of users to check the read information sources, as part of their ability to critically analyze their media literacy. The novelty of this research is that it brings together three important trends related to the way online users consume media information. On one hand there is a new trend of using technology and intelligent systems in order to select and recommend media articles to consumers. There is also a rather traditional view of consuming information about celebrities. On the other hand, we include in the model the need for a more selective way of consuming online news by analyzing the need to check the received information.

The paper begins with a literature review on the main topics included in the paper, namely the development of new technologies mainly artificial intelligence, the actual trends about the present information overload in the online environment and its credibility as well as the way in which celebrities influence consumers' opinion and buying choices. After introducing the conceptual model, the hypotheses and the methodology of the research, the results are presented. A confirmatory factor analysis is performed in order to confirm the factors used in the research. Based on these, four clusters of consumers are determined. For each of the clusters, there is empirically tested the impact of the independent variables technology and AI orientation, the influence of celebrities and the need to check online information on the dependent variable skeptical opinion related to media information. The paper ends with a discussion about future trends based on the research results.

\section{Literature Review}

\subsection{Artificial Intelligence and Consumers}

Artificial intelligence has become an essential part of our lives, as much of our time is nowadays spent in the online environment. From the beginning of AI, there have been many up and down periods marked both by high expectations and disappointments. Russell and Norvig (2016) defined artificial intelligence as systems able to simulate human attributes such as problem solving, speech recognition or learning [6]. However, the development of AI was expected to overcome the status of narrow intelligence. If AI was able to outperform humans only in a limited number of domains, there has always been hope that an artificial super intelligence will be created at some point. The goal of the scientists was to program an artificial intelligence system which would become conscious, self-aware, creative, wise and even sociable. Nowadays, some consider that an artificial intelligence system will only be superior if it would manage to incorporate intuition in its decision-making process. Intuition, defined as a gut feeling or an instinct is in the current state of AI development still seen as a nontransferable human attribute [7]. In the attempt to design robots with closer human-like attributes, scientists considered that an anthropomorphic appearance would positively influence the human-machine interaction [8]. Hence, we can nowadays differentiate between mechanoids, which are robots similar to machines, humanoids, which are perceived as robots with human-like attributes and androids, which are closest to real human appearance [9]. Huang and Rust (2020) defined four levels of artificial intelligence: mechanical, analytical, intuitive and empathetic and then simplified the model by creating three different AI types which would eventually be used to create a human-robot workforce symbiosis-mechanical AI, used mainly for routine activities, thinking AI, used for rich data and feeling AI, which would come in handy for services which require customer interaction [10].

Even if AI's current development is narrowed, humanity is still benefiting from the various supporting applications of AI which contribute every day to our overall welfare. 
Starting from education and information research, where AI's goal is to improve teacher effectiveness and student engagement [11], to healthcare, where the potential of AI to offer medical diagnosis in areas such as radiology, its importance was highlighted by many specialists [12]. At the same time it has applications for several fields such as mobility [13], insurance companies [14] or the energy sector [15]. The future development of AI promises to allow humans to focus on design and integration activities, while AI will assist these activities, offering significant efficiencies while controlling and monitoring processes in real time [16].

But not everyone trusts this theory of future human-machine symbiosis. The lack of trust in AI is highlighted by many authors. For example, Kahn (2017) researched the limitations of $\mathrm{AI}$ in medical healthcare and emphasized that there have been identified several errors in imaging and medical diagnosis performed by AI, which led to doctors' lack of confidence in the technology [17]. The ethical dimensions of AI are building a subject of interest, as issues such as privacy and shared data were widely debated [18]. Other studies revealed that the willingness to trust artificial intelligence systems in hypothetical scenarios is influenced by differences in their level of anthropomorphism [19-21], by the influence of the social circle [22] or the interactions in the organization [23]. The so called "perceived social interactivity" [24] is told to be an important factor which enhances trust in AI, being defined as the perception that an artificial intelligence system is displaying appropriate emotions and is acting according to societal norms, making users feel that they are actually interacting with other humans $[25,26]$. Another study conducted by Gursoy et al. (2019) proposes three factors which influence the willingness to accept the use of artificial intelligence devices: social influence, hedonic motivation and anthropomorphism [27]. Moreover, studies show that trust and control are more easily granted by extravert users [28], which own a higher degree of openness and as such they show a higher interest in novel systems [29]. Other main determinants for acceptance of service robots are the perceived usefulness and the ease to use [30], previous experiences [31] or the cognitive process [32].

However, one of the biggest concerns remains the work displacement caused by automation. Several studies estimate that up to a third of current activities could be replaced by machines by 2030 [33] while AI will most likely reach actual human skills by 2075 [34]. Although AI's development direction promises to augment and not replace the human workforce, the reality shows that most of the manual processes are subject to analysis to ascertain whether they could be automated. This only means that the rapid integration of AI within manufacturing, supply chain and production will cause a rapid increase of unemployment [35]. Moreover, low-cost labor will no longer make up a competitive advantage, as most of the work will be eventually done by robots [36]. As such, the actual human-driven service frontline will soon become technology-driven [24].

\subsection{Credibility of Social Media Information}

The 21st century has been marked by worldwide Internet access, the emergence of social media platforms, the use of smart devices and the widespread digitalization of all activity sectors. These new means have produced major changes on social, economic, and ideological level. Nevertheless, in recent years, these new technologies have been implemented in both organizational and institutional terms, as well as on personal level. While companies have adapted to the new trends in order to explore new business opportunities, including facilitating dialogue with consumers, increasing brand visibility, attracting potential customers or creating a community of supporters around the brand [37], regular users are using these tools and platforms both to interact with other individuals, as well as to inform and share their ideas and experiences in communities that share the same beliefs and concerns.

In addition to the benefits and opportunities created by the emergence of these new technologies, in recent years, it has become increasingly visible that these tools, if not properly regulated at global level, have the potential to cause social imbalance. Meel and 
Vishwakarma (2020) refer to the speed with which content is generated and disseminated on social platforms as to one of the factors that is contributing to these imbalances [38]. Every second, interactions between millions of users create a huge amount of data. This defines an environment in which users are overwhelmed by too much information and data which cannot be managed in short sessions spent online. Moreover, another factor that has attracted the attention of analysts and specialists around the world is the huge volume of user-generated data which is collected, stored and analyzed by online platforms [39]. All this data defines behaviors, perceptions and social values and can be used to manipulate and provoke certain reactions or actions at individual or collective level. Moreover, in recent years, there have been growing global concerns regarding the veracity of information and data which is disseminated in the online environment through websites, social platforms or forums. Meel and Vishwakarma (2020) highlight the difference between traditional media sources, such as news outlets or newspapers, where a validation process has always taken place before a piece of information or news was published, and social platforms that allow users to generate questionable content and access false information [38]. At the same time, the authors notice a decrease in the level of trust related to media, which, unfortunately, did not remain consistent with the verification and validation process of information, but preferred to adapt to current trends. Thus, in the pursuit of views and clicks, the media generates sensational headlines and uses provocative images that, in most situations, mislead readers. This is an additional reason which contributes to the vulnerability of online users.

Fiction and false information have always been part of our society, whether to promote entertainment, politics, or the business environment [40]. However, in the age of the internet false information takes a different form and has a much greater impact [41]. In the online environment, users and consumers can become victims of fake reviews, satire, deception and farce or they can be manipulated through content defined as fake news. Ceron et al. (2021) state that the emergence of social platforms has led to an unprecedented circulation of false information in society [42]. This is more visible in the context of crises such as the COVID-19 pandemic that has tested the social, economic and medical systems around the world. Unfortunately, in a period of uncertainty and fear, social platforms have intensified the problem by generating an excessive amount of false information related to the pandemic and the measures taken in order to combat it [42].

One of the problems noted by Spohr (2017) refers to the fact that social platforms use algorithm-based technologies that allow users to interact with personalized content based on their personal preferences and beliefs or the ones which are accepted in their groups or communities [43]. This method inevitably leads to the creation of so-called "rooms" or "bubbles" in which the content is filtered and adapted according to the level of acceptance among the community. Thus, there is a risk of polarizing the themes and topics of debate and at the same time, it creates an opportunity for false content creators to promote misleading information to a targeted group in order to generate financial or political gains $[43,44]$. This idea is also supported by Ohleiser (2016) who states that online trends are exploited by creators of fake content with the objective of generating profits and making propaganda [45]. Moreover, Bastick (2021) points out that the organic dissemination of false information is amplified by the interest of third parties to gain ideological or financial gains by micro-targeting vulnerable individuals, who in turn become vectors of false content [46]. Moreover, the author believes that the widespread dissemination of false information could lead to social change, affect economic activities and markets and, consequently, threaten democracy. This concern has been highlighted in 2018, when Cambridge Analytica was accused of collecting, analyzing and using the data generated by over 87 million Facebook accounts in order to influence the results in the US presidential elections in 2016 and in the Brexit campaign [47]. In recent years, the phenomenon of manipulating the public opinion through online platforms has become a central theme among scientific researchers, many of them focusing on defining the concept known as "fake news". In this context, Lazer et al. (2018) consider that when defining the concept of fake news, it is necessary to 
differentiate between misinformation and disinformation [48]. The latter is closely linked to the intention to deceive the public opinion. Moreover, it has been found that in most cases the intention of spreading fake news is closely linked to ideological and political implications. This is the main reason that has led to the emergence of public or private fact-checking platforms that analyze and evaluate political statements. Unfortunately, their contribution to the fight against the spreading of fake news related content is still limited, especially in the context of suspicions related to the lack of political objectivity on these websites [49]. Nunes and Correia (2013) believe that in order to rehabilitate users' trust in social platforms and to combat the effects related to online manipulation, it is necessary to detect fake news early [50]. To facilitate this process, Wardle (2017) classified and defined fake news related content in the following categories - satire and parody, misleading content, false connections, false context, impostor content, manipulated content and fabricated content [51]. Certainly, a profound understanding of this negative phenomenon, so harmful for society, will provide us the solution to combat it.

\subsection{Impact of Celebrity Endorsers}

A celebrity is an acclaimed individual who is notable to a specific segment. An individual could get famous for a lot of reasons: It could be on ability, skill, striking accomplishments, or even his look. Friedman and Friedman (1979) believe that a celebrity is a person whose accomplishments are familiar to people in general [52]. Instances of big names are film stars, singers, TV presenters, online media influencers, competitors, and others. McCracken (1989) characterizes a superstar as a person who appreciates public acknowledgment and who employs this acknowledgment in the interest of a purchaser by showing up with it in a notice [53]. This implies that the celebrity uses individual popularity and personal fame to make mindfulness and promote items.

Celebrity Brand Ambassadors are perhaps the most powerful correspondence on the advertising scene [54]. A large portion of its sponsors use this as a persuasive communication tool-advertisers, corporations, organizations, and marketers-to impact or convince their target audiences to buy their products and services [55]. PR and advertising share comparable useful qualities as effective presenting tools [56]. In the past years celebrities have been frequently used as promoters of electronic word of mouth (eWOM) for promoting different brands and products [57].

The testimonials play a significant role in the image of a brand and also in its marketing strategy. Celebrities have a significant impact as a reference group for consumers, by being a good example for these. Their glamourous and luxury life, the items they wear, the cosmetics they use are often imitated and desired by the consumers. Therefore, the products they promote are frequently bought by individuals. For this reason, including celebrity brand ambassadors in the advertising of products or services is a key aspect for the success of any marketing strategy.

Celebrity endorsement is a famous promoting strategy system which grants vendors to take advantage of the fame of the testimonials in supporting their merchandise [58]. This marketing communication tool is perhaps the most well-known and powerful strategy in promotions nowadays. Celebrities are appealing and have affable qualities and also the power to influence. The marketers have become more conscious of the impact superstars have on people and have tackled this into promoting items and services. They believe that this trend is one of the most foremost efficient strategies in promoting [59]. This procedure comes from the late 19th century when endorsers used famous sportsmen for different tobacco companies [60]. The phenomenon grew quickly ever since, with numerous organizations contributing millions of dollars on testimonials like social media influencers, entertainers, competitors and other famous people to promote their services and products. Advertisers invest money into this technique since they believe that underwriting from VIPs makes their products more trustworthy and appealing to customers [61].

A lot of celebrities such as singers, athletes, actors and others are paid huge amounts of money to promote different brands and products. David Beckham signed a contract with 
Adidas for \$160.8 million in 2003; Taylor Swift had a partnership with Coca-Cola in 2014, estimated at a value of around \$26 million; George Clooney marked an arrangement in 2006 with the company Nespresso for $\$ 5.7$ million yearly; Beyoncé also won $\$ 50$ million thanks to the deal with Pepsi; Michael Jordan with Nike Air Jordan and a lot of other testimonials [62]. Companies spend an immense amount of money on celebrity endorsement believing they will gain high recognition for their products, brands, services, and beneficial influence on the customers' purchase intention. So, celebrity brand ambassadors have usually a good impact on the brand evaluation and image. Even though marketing people and pragmatic researchers have established that there are meaningful advantages of the endorsement of celebrities, there are also possible risks of using the celebrity endorsers. Image change, loss of public granting, public controversy or negative image are potential situations that can affect celebrity endorsement in a negative way [60].

According to Singh and Banerjee (2019), the performance of a celebrity support is delivered by a change of representative implications [4]. The socially applicable important implications in the beginning live in the star, they move later to a product, and from this to the purchase situation. To create a solid communication can be considered as an acknowledgement of the endorsement. This communication could be an expressed or self-possessed insight for a product or service and it is given by a certain group different than the originator of the product [63]. The idea of how the VIP endorser influences relates to the way customers see the benefits and characteristics of the product being accepted, along these lines and enlarging its value among customers. Since they trust the famous person which promotes the product or service, humans will in general exchange their feelings towards the superstar to the associated brand [64]. This is the reason celebrity endorsement is considered an efficient marketing tool by which promotors persuade, yet more than that, they make their product or brand progressively shining with the name of the celebrity. Consumers who consider that famous people are genuine models are meant to change their conduct to synchronize by themselves with the celebrity brand ambassadors [65]. This method impacts customer tastes and points of view.

\section{Conceptual Model and Methodology}

The objective of our research is to determine the new trends of consumer typologies regarding their acceptance of new technologies and $\mathrm{AI}$ in particular, their trust and believe in news and social media information and their trust regarding celebrity endorsers. More precisely we have determined the typologies of consumers regarding their skeptical opinion regarding the above mentioned factors.

Hypothesis 1 (H1). There are consumer groups for which the orientation towards technology and AI impact the skeptical opinion regarding media information.

Hypothesis 2 (H2). There are consumer groups for which the trust and influence towards celebrities influences the skeptical opinion towards media information.

Hypothesis 3 (H3). There are consumer groups for which the need to check the information impact the skeptical opinion towards media information.

In order to achieve these objectives, data have been collected from a survey with 66 self-determined items regarding the use and acceptance of new technologies ( 24 items), relation of consumer to online data ( 7 items), the present information means based on social media (23 items) and the influence celebrity endorsers have on brand attitude and preference (12 items). The data has been collected in December 2018, on a randomly selected sample of 252 respondents.

\section{Results of the Factor Analysis}

In order to test the correlations between the items a factor analysis has been performed. The Kaiser-Meyer-Olkin value of 0.837 (Chi-Square $=10,101.8, p=0.000)$ shows a good 
adequacy of the sample. The scree-plot indicates an ideal number of 4 factors, having a cumulated variance of $41.4 \%$. The content of the factors has been determined based on the items with the highest loadings. Taking into consideration the heterogeneity of the topics, all items with loadings $>0.450$ have been considered for the analysis. A total of 7 items have been dropped based on their low loadings. The factors with the included items will be presented in the following.

Factor 1: Technology and AI orientation-The first factor comprises of the items related to the acceptance of new technologies (23 accepted items with loadings $>0.450$ from a total of 25 items), the attitude of consumers related to data collection in the online environment ( 5 accepted items with loadings $>0.450$ from a total of 25 items) and to the general use of social media (6 items).

The items related to the acceptance and use of new technologies and AI include items related to the openness of consumer to adopt new media (0.604), the use of smart-phones and other intelligent devices (0.605), the time spent with the intelligent device (0.632) and the dependency related to the smart-phone (0.526). It also includes items related to the personalization (0.605) and customization (0.662) as well as the availability of creating accounts (0.719) and solving different tasks with the help of the intelligent device (0.595). In this factor there are also included items related to the impact of automated processes (0.671), the receiving of personalized e-mails from intelligent applications (0.585), the curiosity of trying out new technologies (0.625), the possibility of saving time by the use of intelligent systems (0.610). Items with high loadings in this factor include also receiving recommendations based on search history (0.622), the use of virtual assistants $(0.638)$, the user-friendliness of company applications (0.622) and ready to use applications (0.651). The following items included in this factor describe the relation between consumers and AI systems, namely the confidence in AI applications (0.704), easier tasks at home (0.699) and at the job (0.702). Related to the future development of AI, the following items are included in this factor: the replacement of tasks in favor of AI (0.672), future activities done by robots (0.525) and the lower errors rate of AI devices (0.510). The items related to the collection of data in the online environment refer to the use of cookies for easier online activities (0.582), online campaigns based on search history (0.579), personalized advertising (0.572), and easier search on the internet based on cookies (0.578). Related to the general use of social media the following items are included - the use of social media for interaction with other persons (0.473), social media as a source of information (0.572), blogs and online newspaper as a source of information (0.544), online communities as an information source $(0.600)$, customized information on social media $(0.566)$, trust towards the information on social media (0.543) and social media platforms (0.521).

This factor contains a big number of factors showing that many types of attitudes and behavior related to the use of new technologies and AI and online data as well as the use of social media as an information source are correlated. The dropped items refer to being reluctant in delegating tasks to robots or considering robots as a human friend as well as the intrusion in the personal life and possibility of manipulation based on the search history.

Factor 2: Celebrity trend setter-The second factor has been named celebrity trend setter because it includes 8 items which refer to the impact of celebrities used in advertising on the consumers buying behavior and attitude. The items included in this factor refer to consumer which often buy products that are worn or promoted by celebrities $(0.649)$, and those who are paying more attention to commercials which include celebrities $(0.676)$. These behaviors are associated with a better quality for the products promoted by celebrity testimonials (0.716), a better image provided by the products promoted by famous people (0.643) and the belief that celebrities are a guarantee for the quality of the promoted products $(0.730)$. Another statement about celebrity endorsement is regarding the fact that people are seeing the products promoted by celebrities as luxury products $(0.518)$ and that products promoted by celebrities provide a better social status (0.675). The last item makes the association between the consumer and the celebrity endorsers they like, namely that the 
celebrity endorsers have an impact on a brand image only if the consumers likes him/her (0.610).

There are no dropped items for this factor. All these items have high loadings, showing the impact of celebrity brand ambassadors, included in advertising on consumers.

Factor 3: Skeptical opinion regarding media information-The third factor comprises of items related to the skeptical opinion regarding media and information sources related both to the use of social media and the fake news phenomenon ( 4 accepted items with loadings $>0.450$ ) as well as the impact of celebrities on endorsed products and brands ( 4 accepted items with loadings $>0.450$ ).

The items included in this factor refer to the critical opinion regarding the use of social media such as the belief that social platforms are used to manipulate the public opinion (0.455) and the use of social media platforms for the dissemination of fake news (0.549). Among the items in this factor, there are also included the need and desire for developing a legislative framework that should regulate the dissemination of fake news on the internet $(0.480)$ as well as the discomfort created by the encountering of false information (0.553). The items related to the impact of celebrity endorsers include the advantages that celebrities have on a product's image (0.462), the positive or the negative influence from the association between a celebrity and a brand (0.423), the tendency to imitate the behavior of celebrities (0.586) and the consumer's changing preferences depending on the advertised products (0.458).

This factor shows an interesting correlation between items related to the trust in social media information and the impact of celebrities on the endorsed products. Both show that the affiliation or validation of a product or information through a public entity or personality is very important and is directly related to the trust level they develop.

Factor 4: Information validity-Factor 4 provides an overview of the need of validating information which circulates in the public online space and it consists out of 5 items with loadings $>0.400$. The items included in this factor refer to the need to check every piece of information encountered in the written press (0.521), in the online environment $(0.441)$ and the ones read on social platforms (0.402). In this factor, there are also included items regarding the willingness of consumers to pay for both the access to verified and validated information (0.489) and for the removal of false information from the online environment (0556). This factor refers to the negative effects related to the spreading of fake news in the online environment and the willingness of users to implement protection systems against manipulation, even by accessing external support services designed to combat this phenomenon. The items related to the trust typologies have been dropped as neither of them has had sufficient loadings for any of the four selected factors.

The items included in each of the factors can be observed in Table 1.

Table 1. Results of the factor analysis.

\begin{tabular}{|c|c|c|c|c|c|}
\hline & & F1 & F2 & F3 & F4 \\
\hline \multirow{9}{*}{1} & I'm open to change and I'm adapting quickly to new technologies & 0.604 & & & \\
\hline & I constantly use various forms of AI such as smartphones & 0.605 & & & \\
\hline & I'm spending more than half a day connected to technology & 0.632 & & & \\
\hline & Smartphones are indispensable to various professional activities & 0.526 & & & \\
\hline & I personalize my phone and laptop according to my preferences & 0.605 & & & \\
\hline & I prefer customized applications for which I create my own user & 0.662 & & & \\
\hline & I create an account for each application, using my personal data & 0.719 & & & \\
\hline & I solve various administrative tasks with the help of technology & 0.595 & & & \\
\hline & Automation contributes to making processes more efficient & 0.671 & & & \\
\hline
\end{tabular}


Table 1. Cont

\begin{tabular}{|c|c|c|c|c|c|}
\hline & & F1 & F2 & F3 & F4 \\
\hline \multirow{25}{*}{1} & I like receiving personalized emails from various applications & 0.585 & & & \\
\hline & I'm curious about the new technologies and I want to try them out & 0.625 & & & \\
\hline & Technology makes processes more efficient, helps us save much time & 0.610 & & & \\
\hline & I like receiving recommendations based on my search history & 0.622 & & & \\
\hline & $\begin{array}{l}\text { I prefer using virtual assistants than waiting on the phone to be connected } \\
\text { with a call center employee }\end{array}$ & 0.638 & & & \\
\hline & $\begin{array}{l}\text { Smart solutions adopted by the companies are user friendly and can perform } \\
\text { more efficiently the same tasks as human employees }\end{array}$ & 0.622 & & & \\
\hline & I like to receive information from virtual assistants & 0.651 & & & \\
\hline & I have more confidence in systems that use robots & 0.704 & & & \\
\hline & Robots will make my home activities easier & 0.699 & & & \\
\hline & Robots and AI systems will ease my professional activity & 0.702 & & & \\
\hline & Simple work tasks can be replaced with artificial intelligence systems & 0.627 & & & \\
\hline & In 50 years many of the usual activities will be done by robots & 0.525 & & & \\
\hline & Robots and AI systems have a lower error rate than people & 0.510 & & & \\
\hline & Cookies make online activity easier & 0.582 & & & \\
\hline & $\begin{array}{l}\text { I agree to online campaigns saving my search history in order to ease my } \\
\text { online activity }\end{array}$ & 0.579 & & & \\
\hline & $\begin{array}{l}\text { I agree to online companies saving my search history in order to personalize } \\
\text { their publicity campaigns }\end{array}$ & 0.572 & & & \\
\hline & I'm influenced by online public banners & 0.355 & & & \\
\hline & Saving my search history helps me get to the pages I'm looking for & 0.578 & & & \\
\hline & Social networks are a great way to interact with other people & 0.473 & & & \\
\hline & Social networks are an important source of information & 0.527 & & & \\
\hline & Blogs, online publications are a trustworthy source of information & 0.544 & & & \\
\hline & Online communities are a great way to access information of interest & 0.600 & & & \\
\hline & $\begin{array}{l}\text { The information and content accessible on social networks correspond to your } \\
\text { personal interests }\end{array}$ & 0.566 & & & \\
\hline & Content published on social networks has a high degree of trust & 0.543 & & & \\
\hline & I trust the information posted on social networks & 0.521 & & & \\
\hline \multirow{8}{*}{2} & I often buy products that are worn or promoted by celebrities & & 0.649 & & \\
\hline & I pay more attention to advertising campaigns in which celebrities appear & & 0.676 & & \\
\hline & I believe that products promoted by celebrities have a better quality & & 0.716 & & \\
\hline & $\begin{array}{l}\text { Products promoted by celebrities have a better image and are better seen by } \\
\text { the social circle }\end{array}$ & & 0.643 & & \\
\hline & Celebrities are a guarantee for the quality of the promoted products & & 0.730 & & \\
\hline & Products promoted by celebrities can be considered luxury products & & 0.518 & & \\
\hline & I have a better social status, if I wear products promoted/worn by celebrities & & 0.675 & & \\
\hline & I buy a product promoted by a star only if I like that star & & 0.610 & & \\
\hline
\end{tabular}


Table 1. Cont.

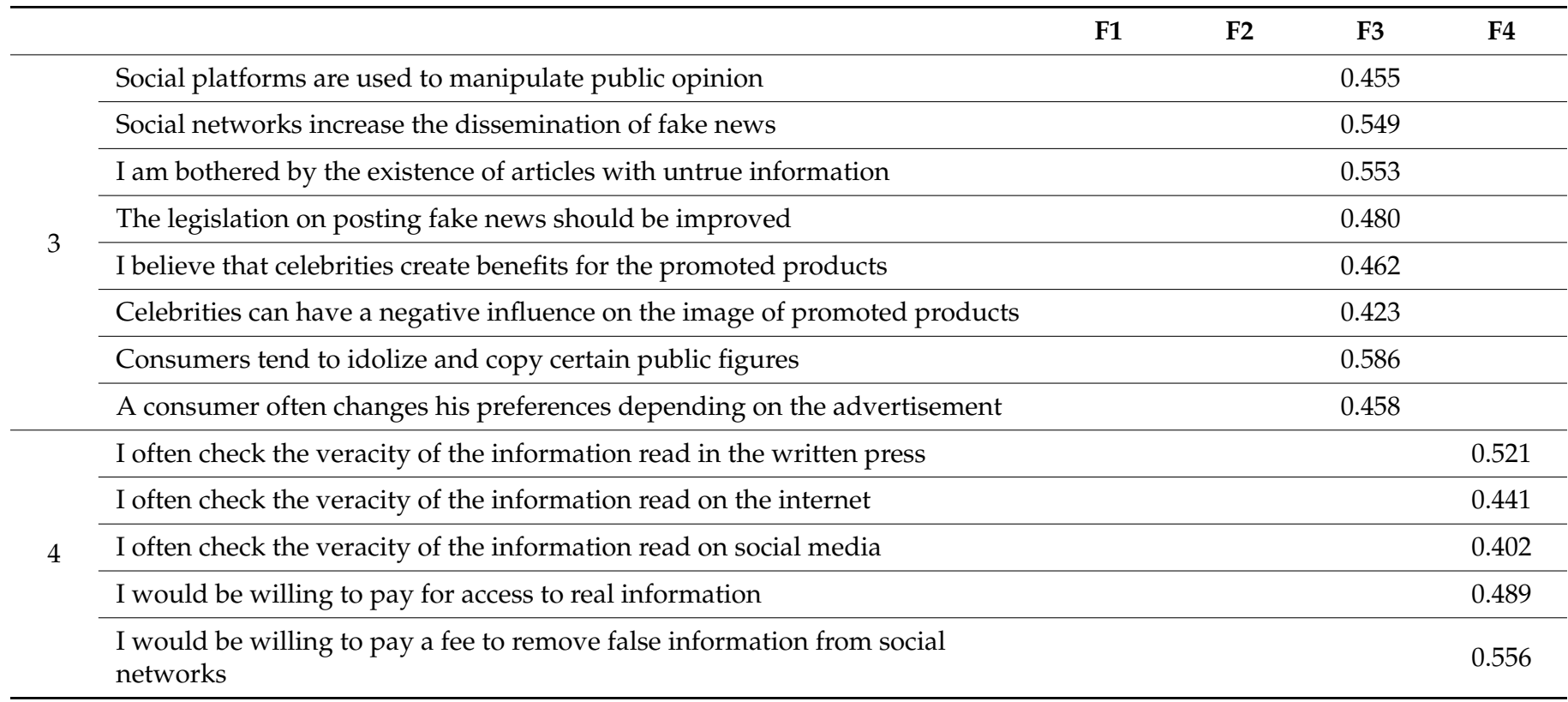

\section{The Overall Regression Model}

In order to test the relation between the variables a regression model has been applied having the skeptical opinion regarding media information as dependent variable, the technology and AI orientation, the impact of the celebrity trend setter and the need for information validity as independent variables. In spite of the fact that all coefficients for the independent variables are significant, two of the variables have a confidence interval which include the value 0 showing a low influence. The overall model has an $R^{2}=0.069$ and $\mathrm{F}=6.160(p=0.000)$. The information validity is the only variable having a coefficient value of $0.140(\mathrm{~T}=2.995, p=0.003)$ and $\mathrm{CI}=[0.048 ; 0.233]$, not including the 0 value. The technology and AI orientation has a positive coefficient having the value $0.107(\mathrm{~T}=1.955$, $p=0.052)$ and a $\mathrm{CI}=[-0.001 ; 0.215]$. The same is valid for the variable celebrity trend setter, for which the coefficient has a positive value $0.083(T=1.840, p=0.067)$ and $C I=[-0.006$; $0.171]$. These results of the overall regression model can be observed in Table 2.

Table 2. The overall regression model.

\begin{tabular}{|c|c|c|c|c|c|}
\hline \multicolumn{6}{|c|}{ Dependent Variable: Skeptical Opinion Regarding Media Information } \\
\hline Independent Variables & $\beta$ & $\mathbf{T}$ & CI & $\mathbf{R}^{2}$ & $\mathbf{F}$ \\
\hline Technology and AI orientation & 0.107 & $1.955 *$ & {$[-0.001 ; 0.215]$} & & \\
\hline Celebrity trend setter & 0.083 & $1.840 *$ & {$[-0.006 ; 0.171]$} & & \\
\hline Information validity & 0.140 & $2.995^{* * *}$ & {$[0.048 ; 0.233]$} & 0.069 & $6.160^{* * * *}$ \\
\hline Constant & 3.802 & $12.603^{* * *}$ & {$[3.208 ; 4.396]$} & & \\
\hline
\end{tabular}

$$
{ }^{* * *} p<0.01,{ }^{* *} p<0.05, * p<0.1 .
$$

Taking into consideration the fact that the independent variables have a good fit for the influence on the skeptical opinion regarding media information, we have tried to test the influence of the variables for different clusters, namely subgroups of consumers. In the following we have performed a hierarchical cluster analysis based on the Ward method and we have tested the same model for each of the four determined subgroups.

\section{Results of the Cluster Analysis}

Based on the averages of the previously determined factors, a hierarchical cluster analysis using the Ward-method has been applied in order to determine the groups of 
consumer with similar behavior and believes. The dendogram has indicated an ideal number of four clusters which will be described in the following. An overview of the average values of the four factors for the determined cluster can be viewed in Figure 1.

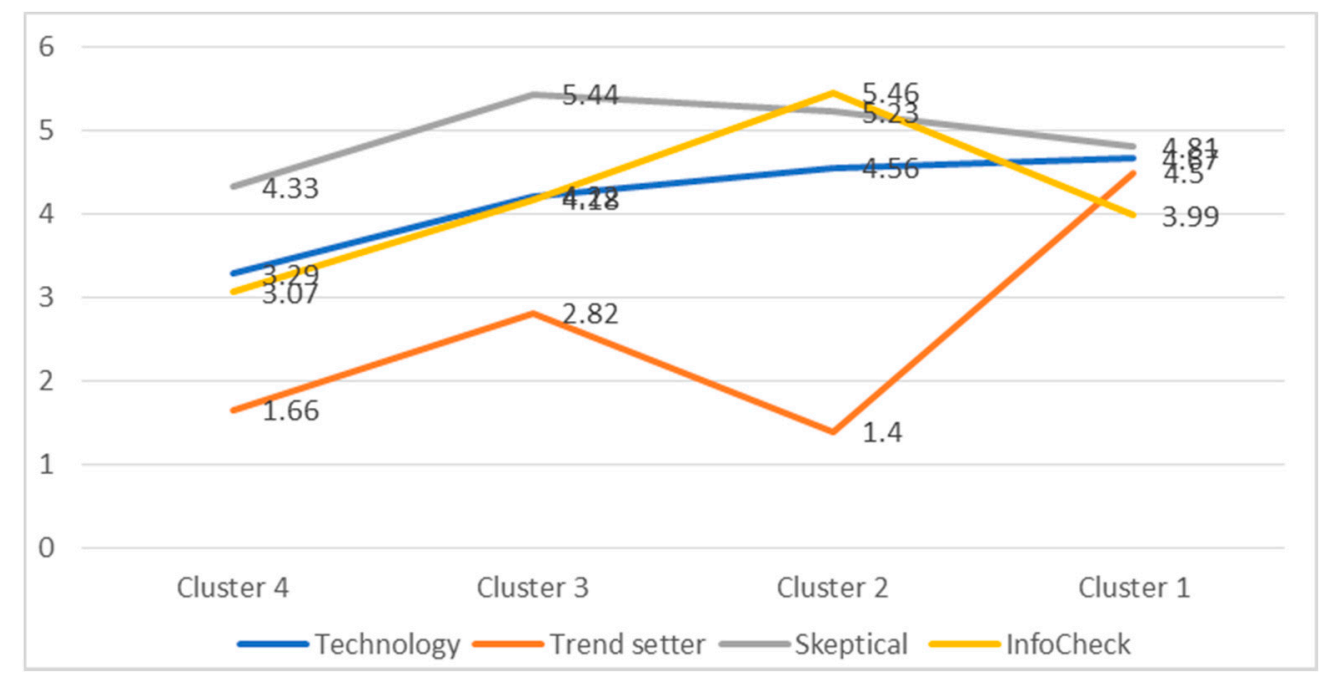

Figure 1. Average factor values for the 4 determined clusters.

\section{Cluster 1: Balanced new trend consumer}

The first cluster has been named the "balanced new trend consumer" as there is an equilibrium between the analyzed factors. This type of consumer has the strongest technological orientation $(\mathrm{M}=4.67, \mathrm{SD}=0.88)$, the strongest orientation towards the influence of celebrities $(\mathrm{M}=4.50, \mathrm{SD}=1.03)$ but an under average need for information check $(\mathrm{M}=3.99$, $\mathrm{SD}=1.06)$ and an under average skeptical opinion related to the information presented in the media $(\mathrm{M}=4.81, \mathrm{SD}=1.24)$. This cluster is predominantly female $(55.3 \%$ female and $44.7 \%$ male) and it is the smallest group from the clusters representing $18.6 \%$ of the total sample.

In order to determine the impact of each factor on the consumers' skeptical opinion, a regression model has been applied, having the skeptical opinion regarding media information as dependent variable and the other three factors as independent variables, as it can be observed in Table 3. For the balanced new trend consumer, the technology and AI orientation has a significant positive value having a coefficient of $0.789(\mathrm{~T}=4.465, p=0.000)$ and a $\mathrm{CI}=[0.433 ; 1.937]$ with positive values. The same is valid for the celebrity trend setter, which has a positive significant coefficient value of $0.294(\mathrm{~T}=2.054, p=0.046)$ and a $\mathrm{CI}=[0.005 ; 0.583]$ with positive values. The information validity has not a significant value for this consumer cluster $(T=-0.124, p=0.902$ and $C I=[-2.192 ; 1.937])$. This cluster has the highest $\mathrm{R}^{2}=0.398(\mathrm{~F}=9.480, p=0.000)$.

Table 3. Regression model for cluster 1.

\begin{tabular}{cccccc}
\hline \multicolumn{6}{c}{ Dependent Variable: Skeptical Opinion Regarding Media Information } \\
\hline Independent Variables & $\boldsymbol{\beta}$ & $\mathbf{T}$ & $\mathbf{C I}$ & $\mathbf{R}^{\mathbf{2}}$ & \\
\hline Technology and AI orientation & 0.789 & $4.465^{* * *}$ & {$[0.433 ; 1.937]$} & & \\
Celebrity trend setter & 0.294 & $2.054^{* *}$ & {$[0.005 ; 0.583]$} & 0.398 & $9.480 * * *$ \\
Information validity & -0.018 & -0.124 & {$[-0.312 ; 0.276]$} & & \\
Constant & -0.217 & 0.902 & {$[-2.192 ; 1.937]$} & & \\
\hline
\end{tabular}

$$
{ }^{* * *} p<0.01,{ }^{* *} p<0.05, * p<0.1
$$




\section{Cluster 2: Skeptical control oriented consumer}

The second cluster of consumer has been named "the skeptical control oriented consumer" as they have the strongest need for information check $(\mathrm{M}=5.46, \mathrm{SD}=0.78)$, a high skeptical opinion on media information both related to fake news and celebrities $(M=5.23, S D=0.78)$, the lowest trust towards the influence of celebrities $(M=1.40$, $\mathrm{SD}=0.56)$ and an over average orientation to technology $(\mathrm{M}=4.56, \mathrm{SD}=0.87)$. This cluster is predominantly masculine (56.9\% male and $43.1 \%$ female) and it represents $20.2 \%$ of the total sample.

For this cluster, none of the three variables have a significant influence on the skeptical opinion regarding media information, having low T-values and CI which include the value 0 as it can be observed in Table 4 . The technology orientation has $\mathrm{T}=1.358(p=0.181)$ and $\mathrm{CI}=[-0.088 ; 0.456]$, the celebrity trend setter has $\mathrm{T}=0.634(p=0.529)$ and $\mathrm{CI}=[-0.295$; $0.567]$ and the information validity has $\mathrm{T}=0.148(p=0.883)$ and $\mathrm{CI}=[-0.274 ; 0.317]$. Besides there is no model fit having $\mathrm{F}=1.142(p=0.342)$ and a low value for $\mathrm{R}^{2}=0.068$.

Table 4. Regression model for cluster 2.

\begin{tabular}{|c|c|c|c|c|c|}
\hline \multicolumn{6}{|c|}{ Dependent Variable: Skeptical Opinion Regarding Media Information } \\
\hline Independent Variables & B & $\mathbf{T}$ & CI & $\mathbf{R}^{2}$ & $\mathbf{F}$ \\
\hline Technology and AI orientation & 0.184 & 1.358 & {$[-0.088 ; 0.456]$} & & \\
\hline Celebrity trend setter & 0.136 & 0.634 & {$[-0.295 ; 0.567]$} & & \\
\hline Information validity & 0.022 & 0.148 & {$[-0.274 ; 0.317]$} & 0.068 & 1.142 \\
\hline Constant & 4.083 & $4.489^{* * *}$ & {$[2.253 ; 5.913]$} & & \\
\hline
\end{tabular}

$$
{ }^{* * *} p<0.01,{ }^{* *} p<0.05, * p<0.1 \text {. }
$$

\section{Cluster 3: Skeptical trend oriented consumer}

The third cluster has been named "the skeptical trend oriented consumer" as the consumers in this cluster have the strongest skeptical beliefs $(\mathrm{M}=5.44, \mathrm{SD}=0.68)$, but they have a lower need for information check $(\mathrm{M}=4.18, \mathrm{SD}=1.10)$, higher trust in celebrities $(\mathrm{M}=2.82, \mathrm{SD}=0.74)$ and an under average technology orientation $(\mathrm{M}=4.22, \mathrm{SD}=0.97)$. This cluster is predominantly feminine (58.4\% female and 41.6 male) and it is the biggest cluster representing $40,0 \%$ of the total sample.

For this cluster, the technology and AI orientation has a significant negative influence on the skeptical opinion regarding media information having a coefficient value of -0.269 $(\mathrm{T}=3.611, p=0.000)$ and $\mathrm{CI}=[-0.417 ;-0.121]$ with negative values. The information validity has a significant negative coefficient value of $-0.128(\mathrm{~T}=-1.955, p=0.053)$, but a confidence interval $\mathrm{CI}=[-0.257 ; 0.002]$ with values around 0 . The influence of the celebrity trend setter is not significant having $\mathrm{T}=-0.682(p=0.497)$ and a $\mathrm{CI}=[-0.235$; 0.115 ] including 0 . The overall model for this cluster has an adequate fit having $\mathrm{F}=4.477$ $(p=0.005)$ and $\mathrm{R}^{2}=0.122$. The results of the regression model can be observed in Table 5 .

Table 5. Regression model for cluster 3.

\begin{tabular}{|c|c|c|c|c|c|}
\hline \multicolumn{6}{|c|}{ Dependent Variable: Skeptical Opinion Regarding Media Information } \\
\hline Independent Variables & $\beta$ & $\mathbf{T}$ & CI & $\mathbf{R}^{2}$ & F \\
\hline Technology and AI orientation & -0.269 & $-3.611^{* * *}$ & {$[-0.417 ;-0.121]$} & & \\
\hline Celebrity trend setter & -0.060 & -0.682 & {$[-0.235 ; 0.115]$} & & \\
\hline Information validity & -0.128 & $-1.955 *$ & {$[-0.257 ; 0.002]$} & 0.122 & $4.477^{* * *}$ \\
\hline Constant & 7.287 & 12.897 & {$[6.166 ; 8.408]$} & & \\
\hline
\end{tabular}

$$
{ }^{* * *} p<0.01,{ }^{* *} p<0.05, * p<0.1
$$




\section{Cluster 4: Indifferent consumer}

The fourth cluster has been named the "indifferent consumer" as it has low average values for all determined factors. These consumers have an under average technology orientation $(\mathrm{M}=3.29, \mathrm{SD}=1.12)$, the lowest skeptical believes $(\mathrm{M}=4.33, \mathrm{SD}=0.75)$, low trust in the influence of celebrities $(\mathrm{M}=1.66, \mathrm{~S}=0.61)$ and an average need for information check $(\mathrm{M}=3.07, \mathrm{SD}=0.89)$. This cluster is predominantly masculine $(54.7 \%$ male and $45.3 \%$ female) and it represents $21 \%$ of the total sample.

For this cluster, none of the variables has a significant influence on the skeptical opinion regarding media information, as it can be observed in Table 6 . The technology and AI orientation has a $\mathrm{T}=-1.328(p=0.190)$ and $\mathrm{CI}=[-0.343 ; 0.070]$ including the value 0 . The celebrity trend setter has $\mathrm{T}=0.551(p=0.584)$ and $\mathrm{CI}=[-0.279 ; 0.491]$, while the information validity has $\mathrm{T}=-1.356(p=0.181)$ and $\mathrm{CI}=[-0.400 ; 0.078]$. Moreover, the relation has a low fit having $\mathrm{F}=1.874(p=0.146)$.

Table 6. Regression model for cluster 4 .

\begin{tabular}{|c|c|c|c|c|c|}
\hline \multicolumn{6}{|c|}{ Dependent Variable: Skeptical Opinion Regarding Media Information } \\
\hline Independent Variables & $\beta$ & $\mathbf{T}$ & CI & $\mathbf{R}^{2}$ & $\mathbf{F}$ \\
\hline Technology and AI orientation & -0.136 & -1.328 & {$[-0.343 ; 0.070]$} & & \\
\hline Celebrity trend setter & 0.106 & 0.551 & {$[-0.279 ; 0.491]$} & & \\
\hline Information validity & -0.161 & -1.356 & {$[-0.400 ; 0.078]$} & 0.103 & 1.874 \\
\hline Constant & 5.105 & 6.848 & {$[3.607 ; 6.603]$} & & \\
\hline
\end{tabular}

\section{Discussion}

The result of our analysis shows that there is an interaction between the beliefs of the consumers regarding the skeptical opinion regarding media information, the technology and AI orientation, the influence of celebrity trend setter and the need for the validation of the received information.

There are two consumer clusters for which the technology and AI orientation have a significant influence on the skeptical opinion regarding media information. For the balanced new trend consumer (cluster 1) a higher orientation towards technology and $\mathrm{AI}$ increases the skeptical opinion towards media information. A higher use of AI and technology increases the awareness of consumers about the possibilities of how intelligent systems can manipulate the media presented on the internet and on social media, thus increasing the skeptical opinion of its content. Cluster 1 represents a group of consumers which are open to the new developments in the society, having in the same time an adequate degree of critical opinion towards these developments and contributing to their equilibrate development. In opposition to this for the skeptical trend oriented consumer, a lower technology and AI orientation increases the skeptical opinion regarding media information. Taking into consideration the fact that for the overall model the influence of the technology and AI orientation has a significant positive value and the fact that cluster 3 has the highest average value for the skeptical opinion regarding media information, probably the negative relation is explained mainly by the high value of the dependent variable. However, a higher skeptical opinion is associated with a lower orientation towards technology and AI orientation. Taking into consideration all these results, it can be stated that H1 is confirmed, having consumer groups for which the orientation towards technology and AI impact the skeptical opinion regarding media information in two directions depending on the type of consumer.

A higher orientation towards celebrity trend setter has an influence on the skeptical opinion regarding media information for the balanced new trend consumer. Taking into consideration that for the overall model the coefficient has a positive significant value, but the confidence interval includes the value 0 , there is a low influence for the overall model. Moreover, the two clusters (cluster 1 and cluster 3) for which significant relations 
have been found between the other variables, have both a higher average value for the variable celebrity trend setter. This can be explained by the fact that the variable skeptical opinion regarding media information includes items about the mistrust towards celebrities. Therefore, $\mathrm{H} 2$ is confirmed for the balanced new trend consumer and for the indirect effect it has on the influences of the other variables.

The need to check the validity of the information has a positive significant influence for the overall model, but no significant influences for the clusters. The need to check the validity of the information is an overall influencing factor, but has different valences for the subgroups of consumers. For instance the only significant coefficient for this variable is for the skeptical trend oriented consumer, but it has a negative value, in opposition to the positive coefficient for the overall model. This confirms that information validity is checked in different ways for the consumer clusters. It can be stated that H3 is confirmed, being a general trend but it is not specific for any of the clusters.

\section{Conclusions}

The skeptical opinion of consumers is related to different actual trends and depends on the characteristics of consumers. The balanced new trend consumer has average values for all determined factors and for this consumer group, the relation between the development of technology and AI as well as the influence of the celebrity trend setter is related to the skeptical opinion regarding media information. This shows a consumer which has a stronger critical thinking, who has the ability to link, in a conscious or unconscious way, different information to the media. For the skeptical trend oriented consumer there is negative relation between the use of technology and AI as well as the need for validation of the read information and the skeptical opinion regarding media information. This can be explained by the higher average values for the skeptical opinion for this cluster. For the other two clusters, no significant relations have been found.

The results show that there are consumer groups who have the ability to link their skeptical opinion regarding media information to other present trends such as the development of technology and AI, the influence of the celebrity trend setter and the need for validating the received information, showing an ability to analyze in a critical way their sources of information. Even though there are also two clusters of consumers who don't link the received information to other current trends, it is important to know that there are consumer who have this ability and it is important to use their critical opinion in order to filter the existing media information.

One important contribution of this research is that it makes a connection between the different developments of our society and prove that no trend comes alone. The results show that any new trend developed in the society has different valances for related fields. In the particular case of this research, it was proven that the technology and AI orientation as well as people who read celebrity news have a more critical and skeptical opinion towards media. This can happen because they are more acquainted with new trends and also have a certain media-literacy that allow them to critically analyze information from the online environment. A general media and technology literacy increases the ability to doubt the credibility of news and filter the received information. In this sense both developments are a good way to combat negative developments such as fake news phenomenon and even the fear that consumers might be manipulated by intelligent systems.

Another important contribution of this research is the possibility to create a consumer segmentation based on several criteria associated with trends from our present society. Knowing the typologies of online consumers can impact management decision for several companies which use AI systems, celebrity endorsement and social media marketing. In order to increase performance, advertisers have to adjust the advertising campaigns design related to content of message, communication channel and even influencer or celebrity endorser, for each of the consumer groups. According to our research results, consumers with a higher media-literacy and stronger orientation towards technology need more accurate messages in order to trust an information from the online environment. Consumers 
who are interested in celebrity news have also a stronger critical and skeptical opinion towards media information. In opposition to this skeptical consumer, there are also groups of consumer who are indifferent to media information and trust easier certain information. This type of consumer has lower critical thought about the received information and trust easier to exaggerated or inaccurate messages.

The limitation of this research lies in the general view of the analyzed variables. Several valances of the variables can be considered for future research. For the consumer groups with higher technology orientation and interest towards celebrities, new constructs can be included, such as ability to critical-thinking or media-literacy, in order to emphasize the reasons behind their skeptical opinion. For the indifferent consumer groups, explorative research has to be performed in order to determine the reasons behind their indifference. However, this research emphasizes the differences between online consumers and the need for different communication messages based on consumer typology, as well as the impact of different present trends for the skeptical opinion of consumers related to online information and news.

Author Contributions: Conceptualization, C.P., M.-I.P., I.E., L.L.; methodology, C.P.; software, C.P.; validation, C.P., M.-I.P., I.E., L.L.; formal analysis, C.P., M.-I.P., I.E., L.L.; resources, C.P., M.-I.P., I.E., L.L.; writing—original draft preparation, C.P., M.-I.P., I.E., L.L.; writing-review and editing, C.P., M.-I.P., I.E., L.L.; visualization, C.P.; supervision, C.P. All authors have read and agreed to the published version of the manuscript.

Funding: This research received no external funding.

Institutional Review Board Statement: Not applicable.

Informed Consent Statement: Not applicable.

Data Availability Statement: Not applicable.

Conflicts of Interest: The authors declare no conflict of interest.

\section{References}

1. Han, L.; Sun, R.; Gao, F.; Zhou, Y.; Jou, M. The effect of negative energy news on social trust and helping behavior. Comput. Hum. Behav. 2019, 92, 128-138. [CrossRef]

2. Lee, S.K.; Lindsey, N.; Kim, K.S. The effects of news consumption via social media and news information overload on per-ceptions of journalistic norms and practices. Comput. Hum. Behav. 2017, 75, 254-263. [CrossRef]

3. Ku, K.Y.L.; Kong, S.Q.; Song, Y.; Deng, L.P.; Kang, Y.; Hu, A. What predicts adolescents' critical thinking about real-life news? The roles of social media news consumption and news media literacy. Think. Ski. Creat. 2019, 33, 100570. [CrossRef]

4. Singh, R.P.; Banerjee, N. Exploring the influence of celebrity worship on brand attitude, advertisement attitude, and purchase intention. J. Promot. Manag. 2018, 25, 225-251. [CrossRef]

5. Visentin, M.; Pizzi, G.; Pichierri, M. Fake news, real problems for brands: The impact of content truthfulness and source credibility on consumers' behavioral intentions toward the advertised brands. J. Interact. Mark. 2019, 45, 99-112. [CrossRef]

6. Russell, S.J.; Norvig, P. Artificial Intelligence: A Modern Approach; Pearson Education Limited: Kuala Lumpur, Malaysia, 2016.

7. Buchanan, L.; O'Connell, A. A brief history of decision making. Harv. Bus. Rev. 2006, 84, 32. [PubMed]

8. Liaw, K.; Driver, S.; Fraune, M.R. Robot sociality in human-robot team interactions. In International Conference on Human-Computer Interaction; Springer: Cham, Switzerland, 2019; pp. 434-440.

9. Gong, L.; Nass, C. When a talking-face computer agent is half-human and half-humanoid: Human identity and consistency preference. Hum. Commun. Res. 2007, 33, 163-193. [CrossRef]

10. Huang, M.-H.; Rust, R.T. Engaged to a robot? The role of AI in service. J. Serv. Res. 2021, 24, 30-41. [CrossRef]

11. Chaudhri, V.K.; Lane, H.C.; Gunning, D.; Roschelle, J. Applications of artificial intelligence to contemporary and emerging educational challenges. AI Mag. Intell. Learn. Technol. 2013, 2, 4.

12. Dreyer, K.; Allen, B. Artificial intelligence in health care: Brave new world or golden opportunity? J. Am. Coll. Radiol. 2018, 15, 655-657. [CrossRef]

13. Ding, I.-J.; Lin, R.-Z.; Lin, Z.-Y. Service robot system with integration of wearable Myo armband for specialized hand gesture human-computer interfaces for people with disabilities with mobility problems. Comput. Electr. Eng. 2018, 69, 815-827. [CrossRef]

14. Alt, M.A.; Saplacan, Z.; Benedek, B.; Nagy, B.Z. Digital touchpoints and multichannel segmentation approach in the life in-surance industry. Int. J. Retail. Distrib. Manag. 2021. Early access. [CrossRef]

15. Ozmen, O.; Sarbu, R.; Saseanu, A.S.; Toader, C. The European Foundation for Quality Management (EFQM) Excellence Model in a in a low voltage switchgear company. Amfiteatru Econ. 2017, 19, 1064-1076. 
16. Makridakis, S. Forecasting the impact of artificial intelligence: The potential effects of AI on businesses, manufacturing, and commerce. Foresight 2018, 49, 18-27.

17. Kahn, C.E. From images to actions: Opportunities for artificial intelligence in radiology. Radiology 2017, 285, 719-720. [CrossRef]

18. Duan, Y.; Edwards, J.S.; Dwivedi, Y.K. Artificial intelligence for decision making in the era of Big Data-Evolution, challenges and research agenda. Int. J. Inf. Manag. 2019, 48, 63-71. [CrossRef]

19. Qiu, L.; Benbasat, I. Evaluating anthropomorphic product recommendation gents: A social relationship perspective to de-signing information systems. J. Manag. Inf. Syst. 2009, 25, 145-182. [CrossRef]

20. Waytz, A.; Heafner, J.; Epley, N. The mind in the machine: Anthropomorphism increases trust in an autonomous vehicle. J. Exp. Soc. Psychol. 2014, 52, 113-117. [CrossRef]

21. Pelau, C.; Ene, I. Interaction between consumers and emerging forms of artificial intelligence: A discriminant analysis. Studia Univ. Vasile Goldis 2020, 30, 1-12. [CrossRef]

22. Pelau, C.; Ene, I.; Pop, M.-I. The impact of artificial intelligence on consumers' identity and human skills. Amfiteatru Econ. 2021, 23, 33-45. [CrossRef]

23. Or, S.; Researcher, I.I.; Tziner, A.; Vasiliu, C.; Ghinea, C.-N. Are positive and negative outcomes of organizational justice conditioned by leader-member exchange? Amfiteatru Econ. 2021, 23, 240-258. [CrossRef]

24. Wirtz, J.; Patterson, P.G.; Kunz, W.H.; Gruber, T.; Lu, V.N.; Paluch, S.; Martins, A. Brave new world: Service robots in the frontline. J. Serv. Manag. 2018, 29, 907-931. [CrossRef]

25. Chattaraman, V.; Kwon, W.-S.; Gilbert, J.E.; Ross, K. Should AI-based, conversational digital assistants employ social- or taskoriented interaction style? A task-competency and reciprocity perspective for older adults. Comput. Hum. Behav. 2019, 90, 315-330. [CrossRef]

26. Dabija, D.C.; Bejan, B.M.; Dinu, V. How sustainability oriented is generation Z in retail? A literature review. Transform. Bus. Econ. 2019, 18, 140-155.

27. Gursoy, D.; Chi, O.H.; Lu, L.; Nunkoo, R. Consumers acceptance of artificially intelligent (AI) device use in service delivery. Int. J. Inf. Manag. 2019, 49, 157-169. [CrossRef]

28. Kidwell, B.; Calhoun, G.L.; Ruff, H.A.; Parasuraman, R. Adaptable and adaptive automation for supervisory control of multiple autonomous vehicles. In Proceedings of the Human Factors and Ergonomics Society Annual Meeting; SAGE Publications: Los Angeles, CA, USA, 2012; pp. 428-432.

29. Rossi, S.; Santangelo, G.; Staffa, M.; Varrasi, S.; Conti, D.; Di Nuovo, A. Psychometric evaluation supported by a social robot: Personality factors and technology acceptance. In Proceedings of the 27th IEEE International Symposium on Robot and Human Interactive Communication (RO-MAN), Nanjing and Tai'an, China, 27-31 August 2018; pp. 802-807.

30. Wang, Y.Y.; Wang, Y.S.; Lin, T.C. Developing and validating a technology upgrade model. Int. J. Inf. Manag. 2018, 38, 7-26. [CrossRef]

31. Morgan-Thomas, A.; Veloutsou, C. Beyond technology acceptance: Brand relationships and online brand experience. J. Bus. Res. 2013, 66, 21-27. [CrossRef]

32. Venkatesh, V.; Davis, F.D. A theoretical extension of the technology acceptance model: Four longitudinal field studies. Manag. Sci. 2000, 46, 186-204. [CrossRef]

33. Manyika, J.; Chui, M.; Miremedi, M.; Bughin, J.; George, K.; Wilmott, P.; Dewhurst, M. A Future That Works: Automation, Employment, and Productivity; McKinsey Global Institute: New York, NY, USA, 2017. Available online: https: / / www.mckinsey. com/featured-insights/digital-disruption/harnessing-automation-for-a-future-that-works (accessed on 12 February 2021).

34. Müller, C.V.; Bostrom, N. Future progress in artificial intelligence: A survey of expert opinion. In Fundamental Issues of Artificial Intelligence; Springer: Cham, Switzerland, 2016; pp. 555-571.

35. Muhuri, P.K.; Shukla, A.K.; Abraham, A. Industry 4.0: A bibliometric analysis and detailed overview. Eng. Appl. Artif. Intell. 2019, 78, 218-235. [CrossRef]

36. Frey, C.B. The Technology Trap: Capital, Labor and Power in the Age of Automation; Princeton University Press: Princeton, NJ, USA, 2019; pp. 297-299.

37. Sánchez-Cobarro, P.D.H.; Molina-Castillo, F.-J.; Alcazar-Caceres, C. The brand-generated content interaction of Instagram stories and publications: A comparison between retailers and manufacturers. J. Theor. Appl. Electron. Commer. Res. 2020, 16, 31. [CrossRef]

38. Meel, P.; Vishwakarma, D.K. Fake news, rumor, information pollution in social media and web: A contemporary survey of state-of-the-arts, challenges and opportunities. Expert Syst. Appl. 2020, 153, 112986. [CrossRef]

39. Busu, C.; Busu, M. The role of knowledge intensive business services on romania's economic revival and modernization at the regional level. Sustainability 2017, 9, 526. [CrossRef]

40. Tantau, A.; Pelau, C.; Pop, M. Fake news in the energy industry. In Proceedings of the 4th BASIQ International Conference on New Trends in Sustainable Business and Consumption 2018 (BASIQ), Heidelberg, Germany, 11-13 June 2018; pp. $204-210$.

41. Burkhardt, J.M. History of Fake News. Libr. Technol. Rep. 2017, 53, 5-9. Available online: https://search-proquest-com.ucd.idm. oclc.org/docview/1967322040/abstract/32BE018C856D42F8PQ/1?accountid=14507 (accessed on 16 March 2021).

42. Ceron, W.; De-Lima-Santos, M.-F.; Quiles, M.G. Fake news agenda in the era of COVID-19: Identifying trends through factchecking content. Online Soc. Netw. Media 2021, 21, 100116. [CrossRef] 
43. Spohr, D. Fake news and ideological polarization: Filter bubbles and selective exposure on social media. Bus. Inf. Rev. 2017, 34, 150-160. [CrossRef]

44. Oncioiu, I.; Popescu, D.M.; Aviana, A.E.; Serban, A.; Rotaru, F.; Petrescu, M.; Marin-Pantelescu, A. The role of environmental, social, and governance disclosure in financial transparency. Sustainability 2020, 12, 6757. [CrossRef]

45. Ohleiser, A. This Is How Facebook's Fake-News Writers Make Money. The Washington Post. 18 November 2016. Available online: https:/ / www.washingtonpost.com/news/the-intersect/wp/2016/11/18/this-is-how-the-internets-fake-news-writersmake-money /?noredirect=on\&utm_term $=.8$ b08a30bb277 (accessed on 16 March 2021).

46. Bastick, Z. Would you notice if fake news changed your behavior? An experiment on the unconscious effects of disinformation. Comput. Hum. Behav. 2021, 116, 106633. [CrossRef]

47. Isaak, J.; Hanna, M.J. User data privacy: Facebook, Cambridge Analytica, and privacy protection. Computer 2018, 51, 56-59. [CrossRef]

48. Lazer, D.M.; Baum, M.A.; Benkler, Y.; Berinsky, A.J.; Greenhill, K.M.; Menczer, F.; Metzger, M.J.; Nyhan, B.; Pennycook, G.; Rothschild, D.; et al. The science of fake news: Addressing fake news requires a multidisciplinary effort. Science 2018, 359, 1094-1096. [CrossRef]

49. Dobbs, M. The Rise of Political Fact-Checking: How Reagan Inspired a Journalistic Movement: A Reporter'a Eye View; Tech. Rep.; New America Foundation: Washington, DC, USA, 2012. Available online: http://newamerica.net/sites/newamerica.net/files/ policydocs/The_Rise_of_Political_Fact-checking.pdf.pdf (accessed on 16 March 2021).

50. Nunes, M.; Correia, J. Improving trust using online credibility sources and social network quality in P2P marketplaces. In Proceedings of the IEEE 8th Iberian Conference on Information Systems and Technologies 2013 (CISTI), Lisbon, Portugal, 19-22 June 2013; pp. 1-4.

51. Wardle, C. Fake News. It's Complicated. First Draft. 16 February 2017. Available online: https://firstdraftnews.org/fake-newscomplicated/ (accessed on 16 March 2021).

52. Friedman, H.H.; Friedman, L. Endorser effectiveness by product type. J. Advert. Res. 1979, 19, 63-71.

53. McCracken, G. Who is the celebrity endorser? Cultural foundations of the endorsement process. J. Consum. Res. 1989, 16, 310-321. [CrossRef]

54. Lim, J.S.; Chock, T.M.; Golan, G.J. Consumer perceptions of online advertising of weight loss products: The role of social norms and perceived deception. J. Mark. Commun. 2018, 26, 145-165. [CrossRef]

55. Martinez-Lopez, F.J.; Anaya-Sánchez, R.; Giordano, M.F.; Lopez-Lopez, D. Behind influencer marketing: Key marketing deci-sions and their effects on followers' responses. J. Mark. Manag. 2020, 36, 579-607. [CrossRef]

56. Ferguson, M.A. Building theory in public relations: Interorganizational relationships as a public relations paradigm. J. Public Relat. Res. 2018, 30, 164-178. [CrossRef]

57. Tobon, S.; García-Madariaga, J. The influence of opinion leaders' eWOM on online consumer decisions: A study on social influence. J. Theor. Appl. Electron. Commer. Res. 2021, 16, 43. [CrossRef]

58. Carlson, B.D.; Donavan, D.T.; Deitz, G.D.; Bauer, B.C.; Lala, V. A customer-focused approach to improve celebrity endorser effectiveness. J. Bus. Res. 2020, 109, 221-235. [CrossRef]

59. Spry, A.; Pappu, R.; Cornwell, T.B. Celebrity endorsement, brand credibility and brand equity. Eur. J. Mark. 2011, 45, 882-909. [CrossRef]

60. Erdogan, B.Z. Celebrity endorsement: A literature review. J. Mark. Manag. 1999, 15, 291-314. [CrossRef]

61. Elberse, A.; Verleun, J. The economic value of celebrity endorsements. J. Advert. Res. 2012, 52, 149-165. [CrossRef]

62. McCann, T. The Highest Paying Celebrity Endorsement Deals of All Time. Greeningz. 2017. Available online: http://www. greeningz.com/entertainment/highest-paying-celebrity-endorsement-deals / (accessed on 16 March 2021).

63. Ateke, B.W.; Onwujiariri, J.C.; Nnennanya, D.A. The relationship between celebrity endorsement and brand image in the fastfood industry in Port Harcourt, Nigeria. Eur. J. Bus. Manag. 2015, 7, 177-186.

64. Schimmelpfennig, C. Who is the celebrity endorser? A content analysis of celebrity endorsements. J. Int. Consum. Mark. 2018, 30, 220-234. [CrossRef]

65. Priyankara, R.; Weerasiri, S.; Dissanayaka, R.; Jinadasa, M. Celebrity endorsement and consumer buying intention with relation to the television advertisement for perfumes. Manag. Stud. 2017, 5, 128-148. [CrossRef] 